\title{
Evaluation of Vibration Profiles for ULD Dollies at Air-Cargo Sorting Hubs
}

\author{
Jay Singh \\ California Polytechnic State University \\ jasingh@,calpoly.edu
}

\author{
S. Paul Singh \\ Michigan State University \\ packlawusa@gmail.com
}

\author{
Koushik Saha \\ California Polytechnic State University \\ ksaha@calpoly.edu
}

\begin{abstract}
This study measured and analyzed the vibration characteristics of an important component of the air package shipping environment which has not been previously studied or included in the pre-shipment testing of packages. This is the movement of packages between aircraft after they are flown in to an airport-hub and being taken into a facility to conduct a sort, or after being sorted as they are transferred back on to aircraft. These transfers at airport-hubs between trucks, building sortation facilities and aircraft are done using material handling equipment called "dollies" or carts. These carts often are connected with each other into small trains and then pulled by tug motors on aircraft tarmacs. This study measured the vibration levels experienced by these carts or dollies with and without packages placed in dollies in two different sizes of carts. The data was analyzed to determine the vibration characteristics. Results show that existing vibration test methods do not cover the significant high levels of vibration that are used to simulate truck and aircraft shipments in accordance with existing vibration test methods developed by American Society of Testing and Materials (ASTM) and International Safe Transit Association (ISTA). This paper provides new data on package handling and movement at airport facilities and tarmacs.
\end{abstract}

Key Words: Vibration, Testing, Packages, Truck, Air Shipments, Carts and Dollies, Airport Handling

\subsection{INTRODUCTION}

Package testing is an important and critical function in the development and successful launch of any new product in the various consumer goods, food and pharmaceutical, hazardous materials, electronics, furniture and appliance industries. It also plays a vital role in the development of packaging methods in both 'business to consumer' as well as 'business to business' delivery of 
products ranging from automotive assembly, avionics, manufacturing to simply the delivery of fresh flowers. In almost all these shipping sectors and many others, shipping packages to the ultimate customer in the shortest possible time and at the highest service rate has become a requirement for all companies. Package testing for the small package environment that mostly consists of shipping using aircraft and trucks between USPS and DHL have become increasingly routine. This short time delivery service often covers vast distances and packages are handled, sorted and shipped in a range of operating equipment. This study focuses on a segment of the air package delivery system to measure and quantify vibration levels to be used for package testing to better replicate this unique and growing shipping environment. The intent of this study is to incorporate the findings into a better package test method for air package testing.

This study focuses on the shipping and handling of packages on airport terminals and hubs used for movement by air cargo operators. Most large airlines offer an air cargo service that moves packages on select cargo or passenger aircraft. The packages may get loaded onto air pallets or air containers which for air shipments are referred to as a unit load device (ULD). The ULD's are then moved either at air-hubs or at airport terminals using tug towing motors and on steel carts. This study revealed through our investigation that these carts or dollies do not have either a good suspension or pneumatic tires. Spring suspensions and air ride suspensions provide damping and attenuation of vibration forces. Also pneumatic tires dampen the road roughness through the structures stiffness, whereas hard wheels like casters transmit high energy. Due to this, they transmit a higher level of vibration intensity (power density levels) into products and packages that are contained inside them. At the onset of the study the authors investigated the movement of such carts and dollies at both a leading air package shipping company as well as an international airport used to move domestic and international cargo. The preliminary results found that packages can travel on these dollies between transfers from a warehouse or sorting facility ranging from a few hundred meters to $3 \mathrm{~km}$. The associated time to transfer the packages using a group of carts or dollies connected as a train behind a tug motor can range from 15 minutes to 3 hours.

This study therefore has collected data specific to this segment of the air package shipping environment that currently is not covered in present-day package testing of consumer products. Previous studies have only focused on shock and drop height data for packages being handled in air package shipping environment $[1,2]$. The requirements and regulations governing the shipment of hazardous materials and dangerous goods for both domestic and international shipments by air also fail to account for these forces. In previous studies of testing of packages to vibration, it has been found that hazardous materials packages can be compromised during shipping and exhibit failure and leaks especially due to loosening of torque or bottle failure for liquids $[3,4]$.

\subsection{AIR CARGO INDUSTRY}

The Airline Deregulation Act of 1978 and the Motor Carrier Act of 1980 removed numerous limitations to allow for the rapid technological change and significant growth development of the US air cargo industry $[5,6]$. Cargo operations and traffic have been influenced, since 1970, by a number of factors such as adoption of unitized loads by the freight industry; integration of production and transportation functions by many 
firms; adoption of highly efficient, low cost and just-in-time techniques by the manufacturing wholesale and retail businesses; and introduction and adoption of wide-bodied aircraft capable of accommodating large unit loads [7]. With restrictions related to key issues such as the cargo amount and proximity to airports where the cargo could be delivered reduced, air cargo has become a very strong component of air transport.

Air cargo has increasingly become a vital part of the global trade and logistics supply chain. While it is interconnected with the other popular modes of transportation - road, rail and water, it differentiates itself through key advantages such as time to travel, value and time-sensitivity of goods being moved, security of goods en route, and guarantee of delivery [8]. It is predicted that the world air cargo traffic will grow at $5.2 \%$ per year over the next 20 years to over 558.3 billion revenue per kilometer (RTKs) by 2031 and the air freight, including express traffic, will average $5.3 \%$ annual growth in terms of RTKs [9].

The air cargo industry is composed of two types of airlines - combination carriers (passenger and cargo) and all-cargo carriers. The all-cargo carriers include integrated freight companies such as FedEx and UPS which carry their own distinction by operating all functions related to cargo shipping trucking, freight forwarding and air transportation whereas other all-cargo carriers only provide air transportation [10] The number of aircrafts in the global freighter fleet is predicted to increase by more than $80 \%$ during the next 20 years as the demand for air cargo services more than doubles [9]. With about $6 \%$ of the global air cargo traffic transported by aircraft, crew, maintenance, and insurance (ACMI) providers, approximately $60 \%$ of the global air cargo is currently carried on freighters [9].
The hub-and-spoke system which led to the evolution of integrated freight companies in the 1970s, was first pioneered by Delta Airlines at its hub in Atlanta, Georgia, USA in 1955 [11]. Huband-spoke systems enabled airlines to serve more markets with the same size fleet as compared to the direct, point-to-point service. At the hubs, travelers could connect to numerous other destinations while using the same airline. In 1971, FedEx launched its overnight parcel delivery services by combining three critical aspects - implementing a hub-and-spoke network, controlling all ground and air facets of the express shipping process and limiting parcel size and weight [10].

Air cargo involves the following key elements [9]:

- Airports: Air cargo requires certain infrastructure at airports for the larger aircraft used as well as sufficient properties on both the airside and landside for cargo facilities. Figure 1 shows the schematic of flows in integrated freight carrier's hub terminal [7]. At facilities like this, the emphasis is on the rapid transfer of freight both through the terminal building as well as across the apron - the space required for parking and maneuvering transient aircraft. Locating the cargo area in close proximity to passenger terminals is advantageous as air cargo also travels ion passenger aircraft. It is estimated that approximately $60 \%$ of all air cargo travels as bellyhold (lowerdeck) cargo on passenger aircraft [12].

- Cargo Operators: Operators for air cargo include integrators (e.g. FedEx and UPS), air cargo aircraft operators (e.g. Polar Express and CargoLux), airline-cargo-specific operators with dedicated aircraft service (e.g. Lufthansa Cargo and Emirates Cargo), passenger airline cargo operations (e.g. United Airlines and 

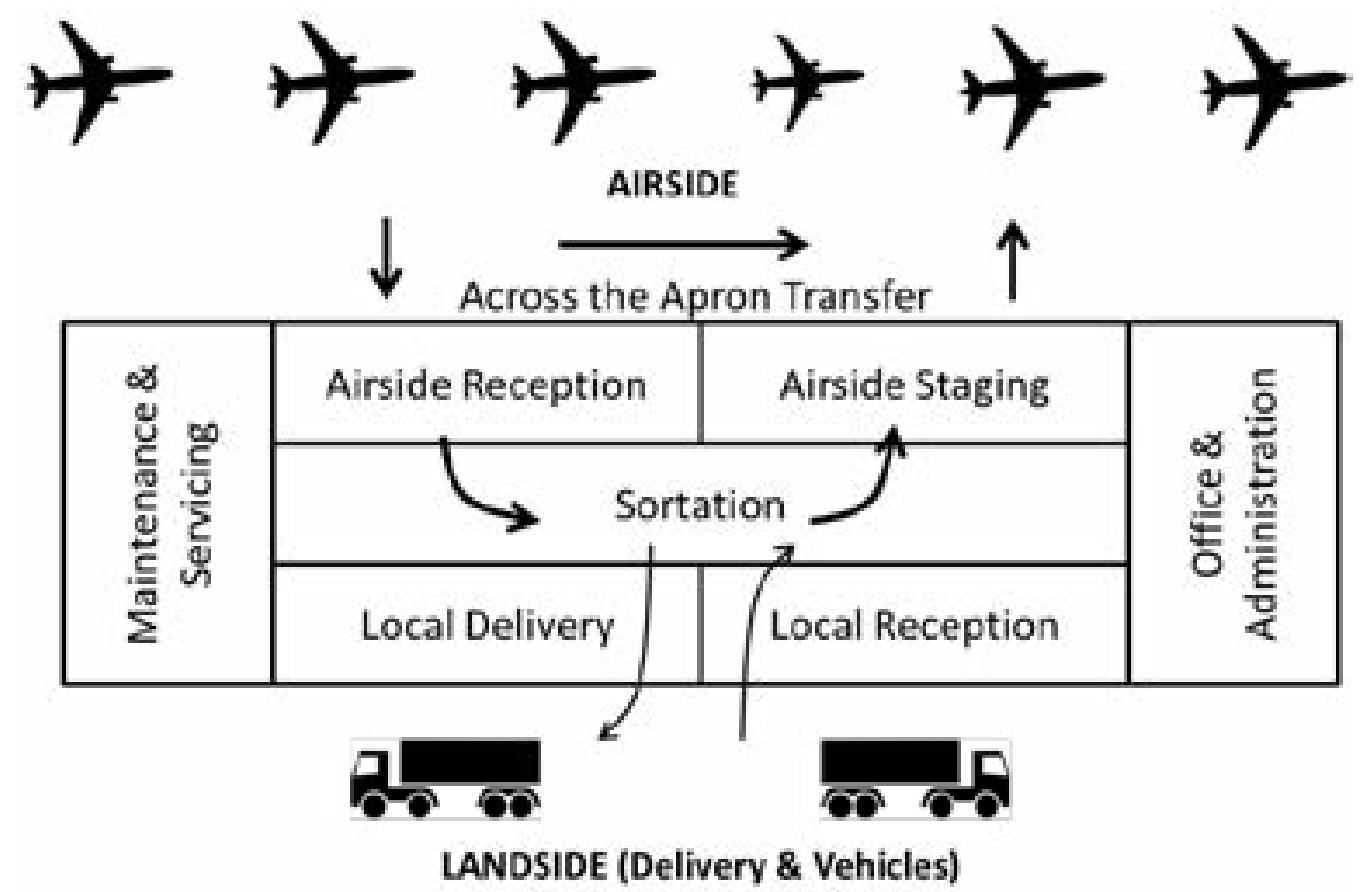

Figure 1: Schematic of Flows in Integrated Freight Carrier's Hub Terminal [7]

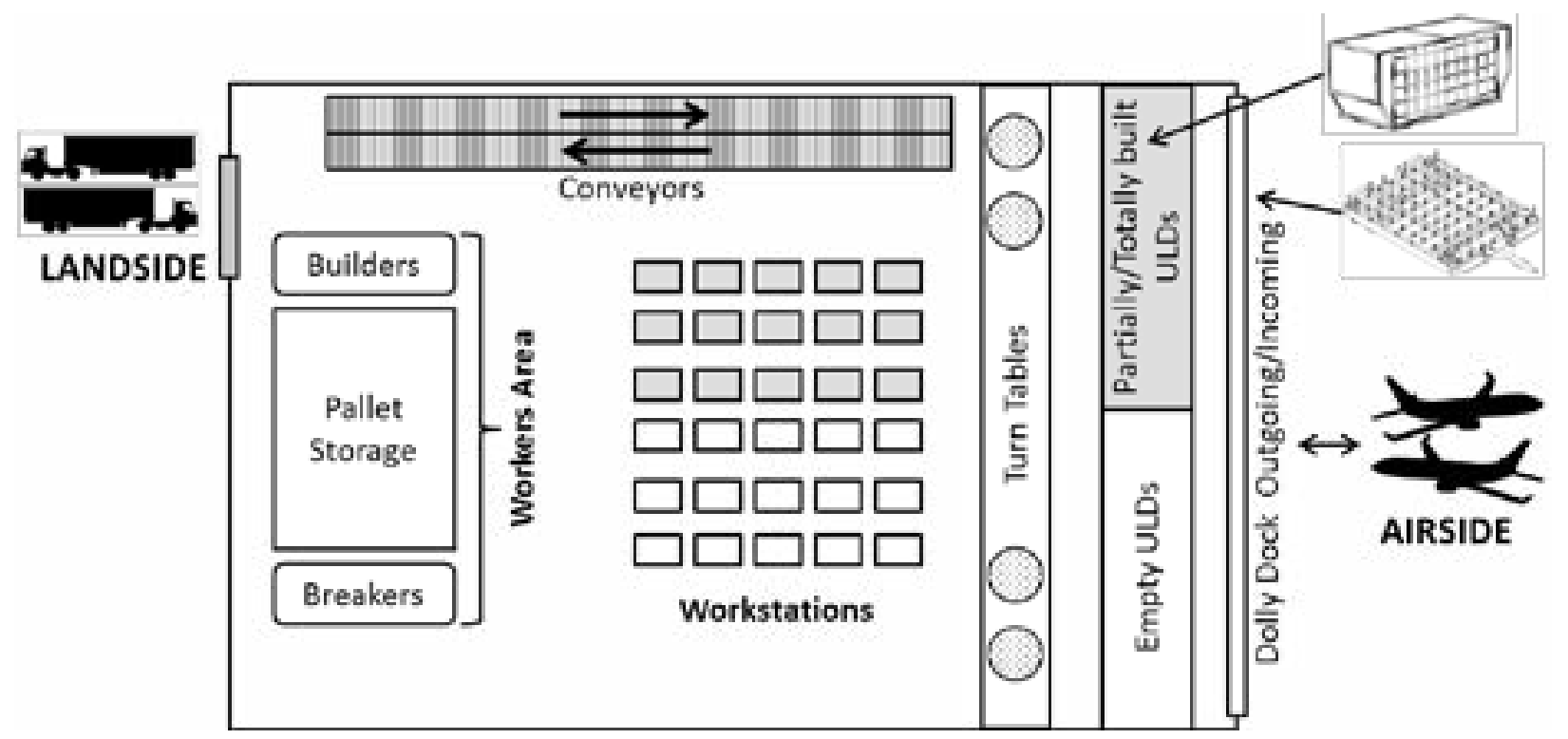

Figure 2: Schematic of Spirit Air Cargo Terminal, Copenhagen [13] 
American Airlines), and freight forwarders (e.g. Kuehne + Nagel and DB Schenker) [8].

- Aircraft: Air cargo shipments consist of unit load devices (ULDs) which can be air containers or pallet loads. The ULDs are configured into different shapes based on the aircraft and loading location on the aircraft. To maximize the volume and take advantage of the bellyhold space of passenger and cargo aircraft, wide bodied aircraft are typically used for air cargo. Fleets typically include aircrafts like Boeing's B747-400, B747-8F, B747-8i, B777 and Airbus A330. While several of these are manufactured in the original freighter version, some narrow body aircraft like Boeing B757 after having served their useful life as passenger aircraft are converted to all freighter combinations.

- Cargo Facilities: The main challenge for cargo facilities is to efficiently move the cargo to and from landside to airside i.e., from trucks to aircraft based on the differences in truck frames and air-cargo dollies (Figure 1) [8]. The cargo facilities essentially pair the requirements of the cargo operators in scale, layout, site plan and level of sophistication of cargo handling and sortation equipment [8]. Following are some details of various cargo operators' facilities:

- Integrators: They have highly customized facilities with dedicated loading and aircraft positions (Figure 1) such as UPS and FedEx's main hubs in Memphis and Louisville respectively.

- General Cargo Facilities: These generally are large warehouses often containing high-bay ULD storage and automated sort and retrieval storage systems [8]. Figure 2 shows a schematic of the Sprit Air cargo handling terminal at Kastrup airport in
Copenhagen [13]. This facility is the leading air cargo career to, from and within Scandinavia and has alliances with Spirit, Lufthansa Cargo, Singapore Airlines Cargo and Japan Airlines Cargo.

- Freight Forwarder: These operations are a combination of cargo warehouse functions and office space for various cargo brokers with typically less air cargo handling equipment.

- Logistics Centers and Value Added Facilities: These accommodate additional logistics and supply chain functions such as making improvements to the product or packaging at the facilities beyond just preparation for shipping and sometimes also include other cargo modes [8].

- Mail Centers: These can be standalone or operate within cargo facilities and include sortation equipment on various levels.

- Cargo: Air cargo has numerous options of containment forms. ULDs are typically a pallet or container used to load luggage, freight and mail on wide-body aircraft and specific narrow-body aircraft. It allows a large quantity of cargo to be bundled into a single unit. Since this reduces the number loaded units, it saves ground crew time and effort and reduces delayed flights. Each ULD has a packing list for content tracking. ULD pallets are typically rugged sheets of aluminum with rims designed to lock onto cargo net lugs (Figure 3). ULD containers, also known as cans and pods, are closed aluminum containers or combinations of aluminum (frame) and Lexan (walls) (Figure 3). Some ULDs also include builtin refrigeration units for perishable products such as fresh produce and pharmaceuticals. Dollies are typically engaged to convey ULDs (pallets and containers) to and from the aircraft 

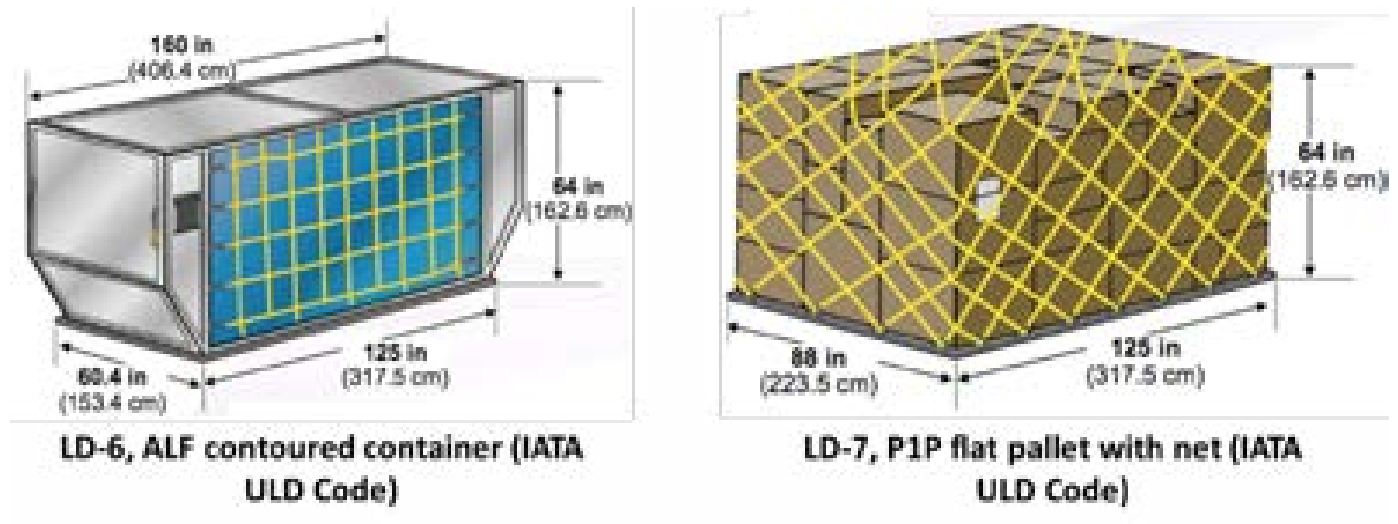

LD-7, P1P flat pallet with net (IATA ULD Code)

Figure 3: ULD Examples: Container (left) and Pallet (right) [16]

and must meet applicable saftey requirements of ISO 6966-1 and ISO 6966-2 [14, 15]. Dollies are equipped with in-built rollers on the deck for acceptance of ULDs for easy retention via built in stops as well as loading and unloading.

Studies have found that integrating operations in air cargo supply chain can lead to improved relations amongst agents and operations [17], it is possible to use data mining methods on logistical state data to filter irregularities and their causes as related to supply chains [18], simulations can be achieved for evaluating and analyzing air cargo facilities [19], stochastic-demand cargo container loading plan models can be employed to minimize the total operating cost [20], and tracking technologies like RFID are appropriate for handling cargos with high value of time as related to the customs clearance process $[21,22]$.

\subsection{AIR CARGO RELATED VIBRATION HAZARD MAPPING}

During the various distribution and handling operations of air cargo, numerous types of hazard elements need to be considered towards successful conveying of goods. These include punctures and abrasion, compression, environmental exposures, shipment handling, shock and vibration [23]. There have been numerous studies that have mapped the vibration profiles as experienced by shipments when using air shipping components in distribution such as those used by integrator cargo operators such as DHL, FedEx and UPS. Typical sources of vibration in these operations include pickup/delivery vehicles, airport dollies and trolleys, material handling equipment such as fork lift trucks, aircrafts and trucks.

A study related to small to mid-sized trucks and automobiles used for delivery and pickup of packages found that while the vibration levels are significantly higher in the vertical axis as compared with the lateral and longitudinal axes for both small trucks and vans, the vertical vibration levels in small trucks are significantly higher than those in vans used for package delivery [24]. As related to the response due to suspensions $(1-10 \mathrm{~Hz})$, the vertical response of interstate truck trailers with leaf spring suspension was observed to be higher than the smaller vehicles studied. However, for structural and higher-frequency responses (10-20 $\mathrm{Hz}$ ), the levels in both the van and the small truck are more severe than in other vehicles.

In different study measured the vibration levels emanating from material handling equipment (MHE) typically used at warehouses and retail stores such as push carts, pallet jacks and forklift trucks 
[25]. It observed that empty carts produced higher vibration levels than the loaded carts; plastic carts showed lower vibration levels than metal carts; and that the vibration level and frequencies measured from MHE occur at a higher frequency $(8-30 \mathrm{~Hz})$ as compared to most transportation vehicle vibrations (2-8Hz). The current ASTM Random Vibration Standards currently do not test at these levels.

Another research compared the vibration profiles for truck vibration for leaf spring and air ride suspensions [26]. The study observed that the air ride truck vibration levels were significantly lower than the leaf spring truck vibration levels. The highest Grms for the 30\% high leaf spring data showed a Grms level of $0.89 \mathrm{G}$ while the same for air ride data showed a Grms level of $0.50 \mathrm{G}$. A study conducted towards collecting data from air ride trucks and airplanes concluded that the airplane profile showed low vibration levels and resulted in its omission in all air parcel shipment test protocols recommended from the study that included trucks, dollies and aircraft [27].

Based on the available data from other modes of transport, the authors of this research investigated the type of metal dollies and carts used to move both domestic and air packages at airports. In this investigation the authors reviewed the equipment as well as interviewed representatives of commercial air cargo and parcel delivery companies, passenger airlines, as well as representatives of the Federal Aviation Administration. Based on this it was found that packages may spend up to an hour traveling in the material handling devices referred to as carts or dollies between an aircraft and the sorting facility as they are affixed to other carts and moved together in a "train" being pulled by a tug motor. As such, based on a package that may go through more than one sort at an airport terminal, and require both loading and then re-loading, the amount of time spent, and the corresponding exposure to vibration from this environment can be significant. It is therefore important to study this environment, and also incorporate it into package test specifications if the levels in this segment are higher.

\subsection{MATERIALS AND METHODS}

\subsection{INSTRUMENTATION AND SET-UP PARAMETERS}

This study measured and analyzed vibration levels in dollies commonly used to transport

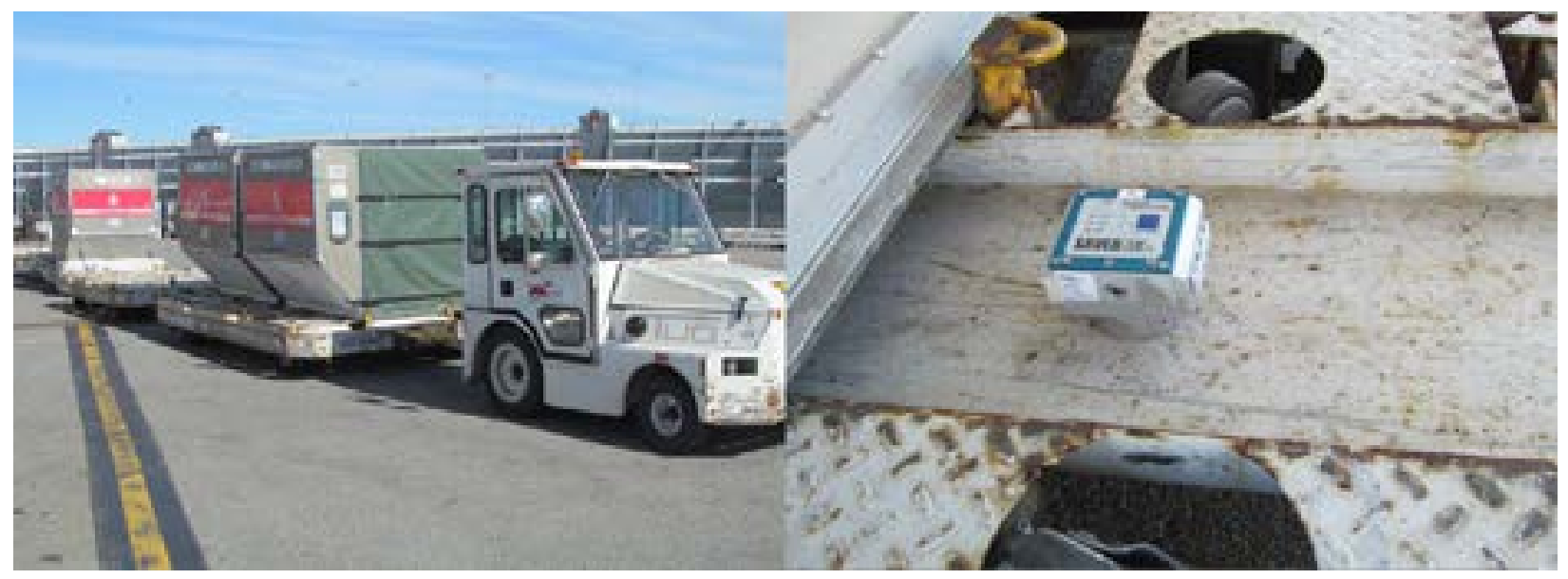

Figure 4: Instrumentation of dollies with SAVER $3 X 90 ®$ data Loggers 
packages in air shipments (Figure 4). Using data recorders, the researchers monitored vertical, lateral and longitudinal vibrations for 50 minutes on a pre-determined path within the premises of a cargo handling operation at an international airport in the US. The study presents this data as power density (PD) spectra and compares it with previously measured PD vibration levels in commercial long-haul interstate tractor-trailer truck shipments. The dollies were moved for an approximate distance of $2 \mathrm{~km}$ around the travel path used by these vehicles to move air cargo at the San Francisco Airport. The equipment for this study was provided by Emirates Air Cargo. The travel speed of these vehicles and dollies shown in Figure 4 was between $1-10 \mathrm{~km} / \mathrm{h}$.

For measuring vibration and transient shock levels describing the physical environment, the

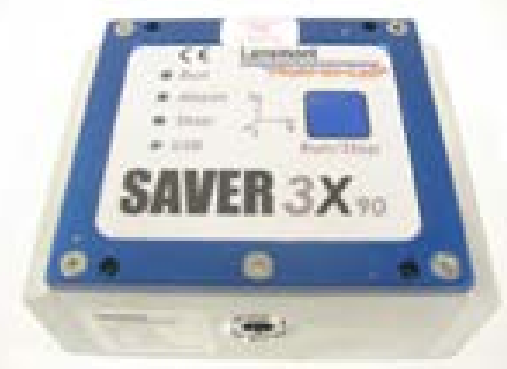

Figure 5 Vibration Recorder (SAVER 3X90®)

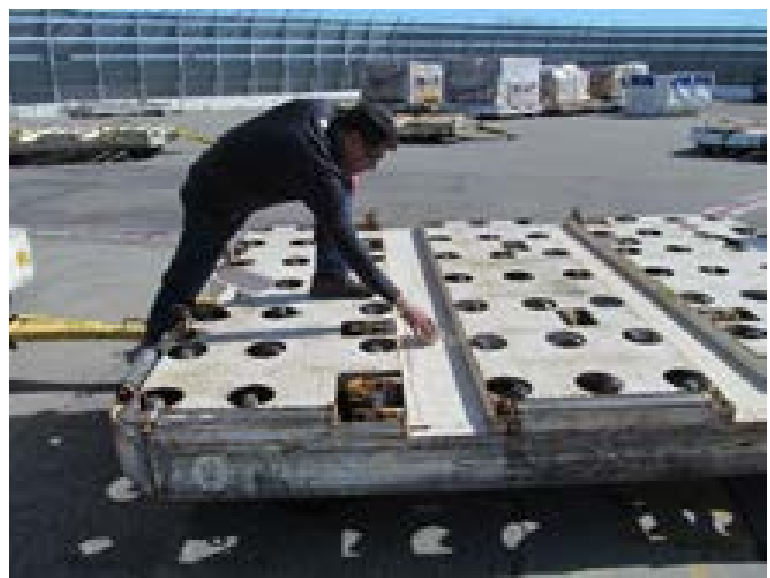

Figure 6: Mounting of recording devices on carts equipment used was a SAVER 3X90 (Figure 5) manufactured by Lansmont Corporation (Monterey, CA, USA). This recorder has a triaxial accelerometer to measure the vibration levels for vertical, lateral and longitudinal movements. These were mounted at the on the floor of the trailer carrying the ULD in the front position of the containers as shown in Figure 4 to prevent minimum obstruction to loading and unloading of palletized cargo in and out of the container. The frequency response of the mounting structure consisted of magnets and steel had a frequency response higher than $250 \mathrm{~Hz}$. Therefore, it did not contribute or filter the data collected. Figure 6 shows the mounting of recorders on the actual carts and dollies.

The recording parameters were as follows:

- Signal-triggered event threshold level: $0.5 \mathrm{G}$

- Signal event size: 1.024

- Pre-trigger data: $50 \%$

- Post trigger: $50 \%$

\subsection{RESULTS AND DISCUSSIONS}

The authors have analyzed vibration data in previous major studies using SAVER software and a methodology developed with Lansmont Corporation in pervious publications $[1,2,24$,

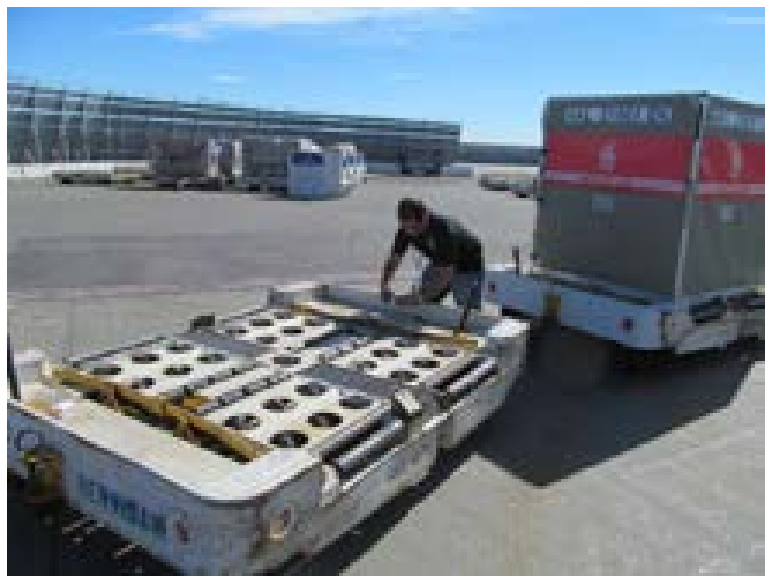




\begin{tabular}{|c|c|c|c|c|c|c|}
\hline \multirow[b]{2}{*}{ Dolly No. } & \multirow[b]{2}{*}{$\begin{array}{c}\text { Dolly } \\
\text { Size }\end{array}$} & \multirow[b]{2}{*}{$\begin{array}{c}\text { Dolly } \\
\text { Weight } \\
\text { (Kg) }\end{array}$} & \multicolumn{3}{|c|}{ ULD Container } & \multirow[b]{2}{*}{$\begin{array}{c}\text { Total Weight } \\
\text { (Kg) (Payload + } \\
\text { Dolly) }\end{array}$} \\
\hline & & & $\begin{array}{c}\text { Tare } \\
\text { Weight } \\
\text { (Kg) }\end{array}$ & $\begin{array}{c}\text { Net } \\
\text { Weight } \\
(\mathbf{K g})\end{array}$ & $\begin{array}{c}\text { Total } \\
\text { Weight } \\
\text { (Kg) }\end{array}$ & \\
\hline \multirow{2}{*}{ Al } & \multirow{2}{*}{ Large } & \multirow{2}{*}{1170} & 56 & 382 & 438 & \multirow{2}{*}{1922} \\
\hline & & & 52 & 258 & 314 & \\
\hline A2 & Large & 1170 & - & - & - & 1170 \\
\hline Bl & Small & 746 & 56 & 328 & 384 & 1130 \\
\hline B2 & Small & 746 & - & - & $\cdot$ & 746 \\
\hline
\end{tabular}

Table 1: Dolly and ULD Container Specifications

$25 \& 26]$. The data obtained from the recorders were analyzed to determine the power density (PD) levels of vibration associated with a given frequency in all three orientations (vertical, lateral and longitudinal). The Power Density (PD) represents the intensity of vibration that occurs on the vehicle floor where packages are commonly placed during transportation. A plot representing the PD levels at various frequencies is referred to as a Power Density Spectrum.

Figures 7 (page 24) compares the Power Density Spectrums developed based on the measured data for the larger sized dolly in the vertical orientation with and without the loaded ULD. Similarly Figure 8 (page 24) shows the vibration levels in a power density spectrum for the smaller dollies when empty and with a loaded ULD.

While the two types of dollies exhibit a different vibration history as expected due to differences in structure, size and stiffness, they do show a similar high frequency and high energy level between 50 to $80 \mathrm{~Hz}$. This is attributed to the rigid caster type wheels that are connected with bearings to the steel carriage of the dolly without any suspension. Also these dollies are rarely equipped with pneumatic tires and therefore create a higher input vibration into products being carried on them.
Figures 9, 10, 11 and 12 (page 24)showing lateral and longitudinal $\mathrm{PD}$ for both seizes of dollies. It is clear that the most significant vibration in this mode of transport is vertical.

\subsection{CONCLUSIONS}

The study concludes the following:

1. High levels of vibration exist in the movement of packages in dollies and carts

2. The high levels of vibration between 50 and $80 \mathrm{~Hz}$ do not exist in either truck or airplane shipments. This type and level of vibration is different and due to its high level can cause damage or package failures.

3. New test methods that incorporate this unique component of transfer of packages in an air parcel shipment on carts and dollies needs to be included in vibration and transportation testing to better design package systems and prevent failures and leaks for dangerous goods.

These results are now being considered by the FAA to be included in an air parcel shipment test. 


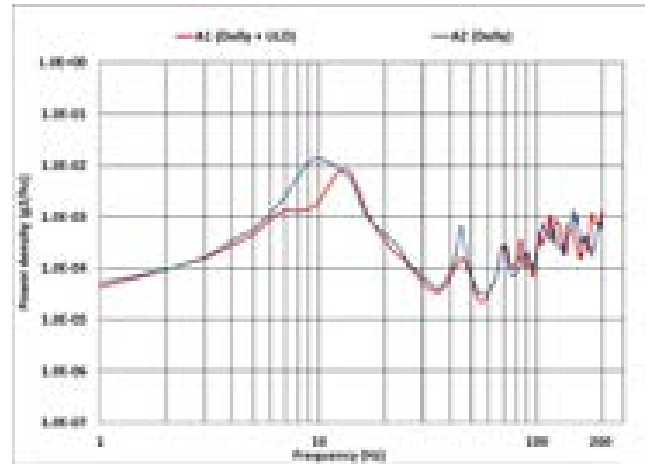

Figure 7: Power Density Spectrum of ULD Container and Large Dolly in Vertical Axis

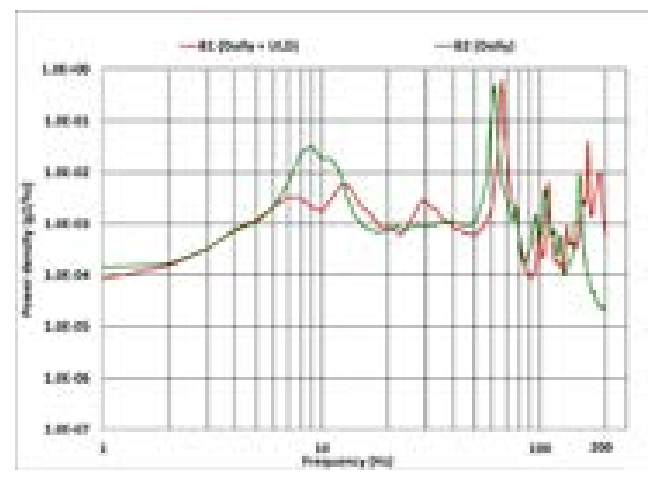

Figure 8: Power Density Spectrum of ULD Container and Small Dolly in Vertical Axis

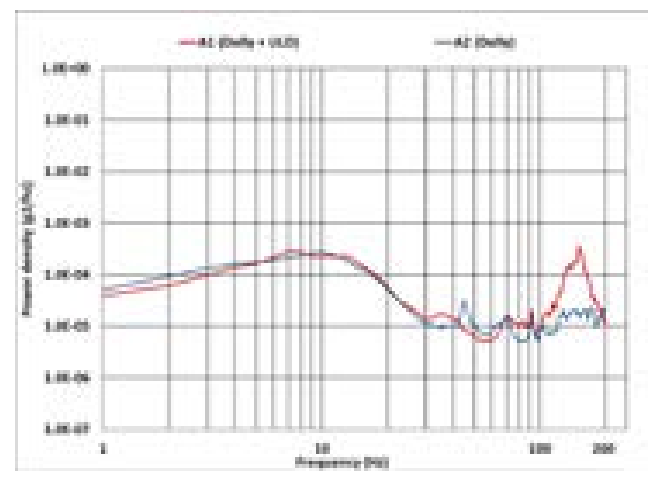

Figure 9: Power Density Spectrum of ULD Container and Large Dolly in Longitudinal Axis

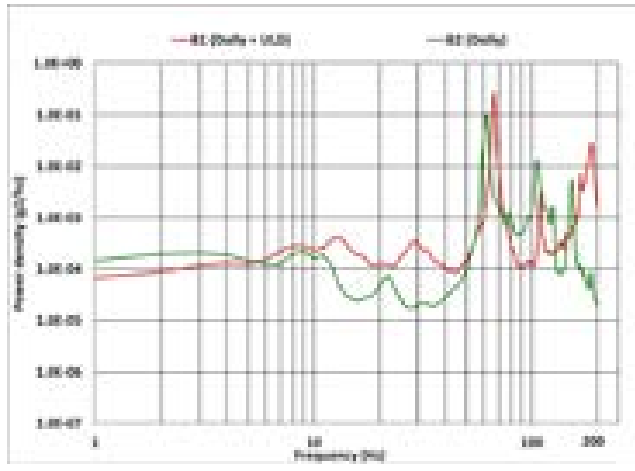

Figure 10: Power Density Spectrum of ULD Container and Small Dolly in Longitudinal Axis

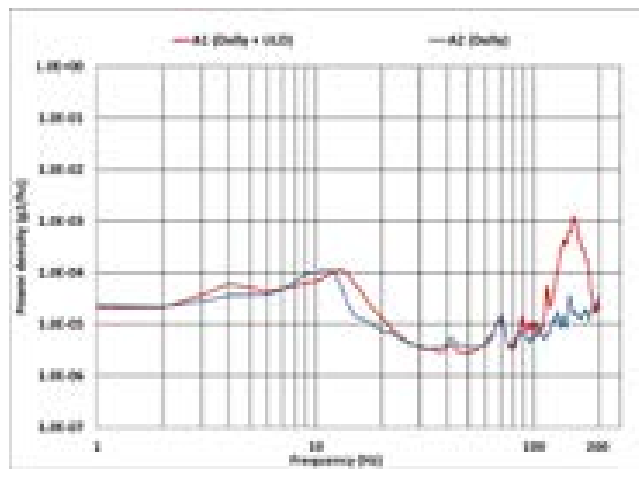

Figure 11: Power Density Spectrum of ULD Container and Large Dolly in Latitudinal Axis

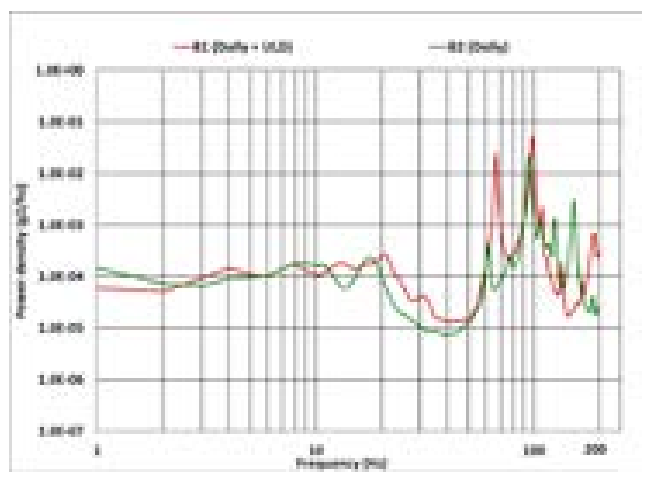

Figure 12: Power Density Spectrum of ULD Container and Small Dolly in Latitudinal Axis 


\section{REFERENCES}

[4] Singh, S. P., G. Burgess, J. Singh and M. Kremer, "Measurement and Analysis of Next Day Air Shipping Environment for Mid Sized and Light Weight Packages for DHL, FedEx and USPS", Journal of Packaging Technology and Science, John Wiley and Sons, Vol. 19, 2006.

[5] Saha, K., Singh, J., Singh, S. P. "Measurement, Analysis and Comparison of Drops Experienced by Packages in Inter-State and Intra-State Next Day Shipments in United States," Journal of Applied Packaging Research, Vol. 4, No. 2, April 2010

[6] Singh, S. P., G. Burgess, and J. Singh, "A New Test Method and Pictorial Markings for Packages Containing Liquid Dangerous Goods in High Altitude Shipments" Journal of Testing and Evaluation, Vol. 32, No. 5, American Society for Testing and Materials, 2004.

[7] Singh, S. P., G. Burgess, and J. Singh, "Package Performance Testing of Dangerous Goods in High Altitude Shipments" Packaging Technology and Science, 16: 119-130, 2003.

[8] Borenstein, S., \& Rose, N. L. (2013). How airline markets work... or do they? Regulatory reform in the airline industry. In Economic Regulation and Its Reform: What Have We Learned?. University of Chicago Press

[9] Trick, S., \& Peoples, J. (2012). Union compensation following intrastate deregulation: Evidence from the US trucking industry. Transport Policy, 24, 10-18.
[10] Ashford, N. J., Mumayiz, S. and Wright, P. H. (2011). Airport Engineering: Planning, Design and Development of 21st Century Airports, 4th Edition. E-Book, ISBN: 978-1-118-00547-7. 457-488

[11] New York Metropolitan Transportation Council (2013). NYMTC Regional Freight Plan Update 2015-2040 Interim Plan, Task 2.1.4 - Air Cargo Network and Infrastructure. LINK. Accessed April 4, 2014.

[12] Boeing (2014). World Air Cargo forecast 2012-13. LINK. Accessed April 4, 2014.

[13] Donatelli, D. J. (2011). Evolution of US Air Cargo Productivity. Unpublished Master of Science thesis, Massachusetts Institute of Technology, Cambridge, Massachusetts, USA

[14] Delta Airlines (2011). Delta Air Lines Newsroom - Press Kit. LINK. Accessed April 4, 2014.

[15] Global Air Cargo Advisory Group (2011). Role of Air Cargo Industry. LINK. Accessed April 4, 2014.

[16] Villa, P. J. and Ortoll, N. R. (2008). Optimization of a Cargo Terminal. Unpublished Master Thesis, Department of Management Engineering, Technical University of Denmark, Lyngby, Denmark.

[17] International Organization for Standardization (2005). ISO 6966-1:2005: Aircraft ground equipment -- Basic requirements -- Part 1: General design requirements. ISO, Geneva, Switzerland

[18] International Organization for Standardization (2005). ISO 6966-2:2005: Aircraft ground equipment -- Basic requirements -- Part 2: Safety requirements. ISO, Geneva, Switzerland 
[19] http://www.searates.com/, Accessed April 7, 2014 LINK.

[20] Bernal, M. P., Blasco, S. B., Pellicer, E. L., González, R. S. (2012) Optimization of the air cargo supply chain. Journal of Airline and Airport Management, North America, Vol. 2, No.2. Available at: LINK. Accessed April 7, 2014.

[21] Brandau, A. and Tolujevs, J. (2013) Modelling and Analysis of Logistical State Data. Transport and Telecommunication. Volume 14, Issue 2, Pages 102-115

[22] Nsakanda, A. L., Turcotte, M. (2004) Air Cargo Operations Evaluation and Analysis through Simulation, in: Proceedings of 2004 Winter Simulation Conference, USA, 2004, pp.1790-1798

[23] Yan, S., Shih, Y.L., Shiao, F.Y., 2008. Optimal cargo container loading plans under stochastic demands for air express carriers. Transportation Research E 44, 555-575.

[24] Hsu, C.-I., Shih, H.-H., Wang, W.-C. (2009) "Applying RFID to reduce delay in import cargo customs clearance process", Computers \& Industrial Engineering, Vol.57 No.2 pp506-19

[25] Lopes, O. A. (2010) RFID and the Internet of Things in Freight and Handling Operations. Unpublished Master Thesis. Department of Management and Industrial Strategy. Lisboa School of Economics \& Management, Lisboa, Portugal

[26] United parcel service of America, Inc. (2005) Air Freight Packaging Pointers. Available at: LINK. Accessed April 7, 2014.
[27] Chonhenchob, V., Singh, S.P., Singh, J.J., Stallings, J., Grewal, G., 2012. Measurement and analysis of vehicle vibration for delivering packages in small-sized and medium-sized trucks and automobiles. Packaging Technol. Sci. 25 (1), 31-38.

[28] Singh, S. P., Singh, J., Gaur, P and Saha, K. (2007) Measurement and Analysis of Vibration Levels on Warehouse and Retail Store Material Handling Equipment. Journal of Applied Packaging Research, Volume 2, Issue 2, December 1, 2007, pages 103-120.

[29] Singh, J., Singh, S. P. and Joneson, E. (2006), Measurement and analysis of US truck vibration for leaf spring and air ride suspensions, and development of tests to simulate these conditions. Packag. Technol. Sci., 19: 309-323

[30] Wallin, B. (2007), Developing a Random Vibration Profile Standard. Proceedings of 2007 IAPRI Symposium, Windsor, UK 